\title{
Morphogenetic Plasticity of Neuronal Elements in Cerebellar Glomeruli during Deafferentation-Induced Synaptic Reorganization
}

\author{
József Hámori, Robert L. Jakab ${ }^{1}$ and József Takács \\ Department of Anatomy, Laboratory of Neurobiology, Semmelweis University, Medical School, \\ Budapest, Hungary, H-1094; \\ 'Section of Neurobiology, Yale University School of Medicine, New Haven, CT, USA
}

\begin{abstract}
SUMMARY
Reorganization of the cerebellar glomerulus, the main synaptic complex within the granule cell layer, was investigated using quantitative morphological techniques. All afferents to the cerebellar cortex, including mossy-fibers, were surgically destroyed by undercutting the cerebellar vermis. Fifteen days after the operation, which resulted in the removal of the main excitatory afferent to the glomerulus, a significant reorganization of the whole synaptic complex was observed, whereas the structural integrity of the glomerulus was remarkably well preserved. This was indicated by the observation that the number of granule cell dendrites ( $\approx 50$ per glomerulus), as well as the number of dendritic digits $(\approx 210$ per glomerulus) bearing most of the $\approx 230$ synaptic junctions per glomerulus, did not change significantly after mossy-fiber degeneration. The total number of synapses in the reorganized glomerulus did not change either, despite the disappearance of two-thirds of (excitatory) synaptic junctions caused by mossy-fiber degeneration. In the reorganized glomeruli, however, the inhibitory, GABA-containing Golgi axonal varicosities became the dominant synaptic type-about four-fifths $(\approx 200)$ of all synapses within the glomerulus-whereas the dendritic synapses between the granule cells
\end{abstract}

\footnotetext{
Reprint address:

Prof. J. Hámori

Department of Anatomy, Semmelweis Medical University

Tüzoltó 58, H-1094 Budapest, Hungary

Fax: +36-1-217-6937
}

represented only one-fifth of all synaptic junctions. The quantitative data of the reorganized cerebellar glomerulus demonstrate both a remarkable constancy and a plasticity of the excitatory granule cells and inhibitory Golgi neurons building up this synaptic complex. Constancy (the preservation of certain specific structural features) is represented by an eventually unchanged number of dendrites and synaptic junctions within the deafferented glomerulus. Such constancy was made possible, however, by the morphogenetic plasticity of both nerve-cell types to produce new, dendrodendritic and axo-dendritic synapses to compensate for the loss of mossy-fiber synapses.

\section{KEY WORDS}

cerebellar cortex, deafferentation, synaptic plasticity, quantitative EM

\section{INTRODUCTION}

Morphological evidence for the plasticity of neuronal networks or nerve cells in the adult brain is provided by the observation that certain neurons in the central nervous system (CNS) maintain their potential to form new synaptic junctions in response to deafferentations or lesions. The resulting neosynaptogenesis is called induced or reactive synaptogenesis /19/.

Two morphologically distinct types of reactive synaptogenesis have been described in the adult CNS. The axonal type of synaptogenesis has been demonstrated in many regions; for example, after denervation of septal nuclei $/ 23,24 /$, hippocampus $14,15,30,31 /$, red nucleus $/ 1,20,24 /$, among others. 
In axonal reactive synaptogenesis, the emphasis is on the active role of axonal processes to find and to reoccupy the deafferentation-caused, vacant, postsynaptic sites. The second, dendritic type of reactive synaptogenesis implies the active participation of postsynaptic dendritic processes in forming new synapses $/ 7,8,32 /$.

The most spectacular example of dendritic reactive synaptogenesis was seen in the lateral geniculate nucleus $/ 10 /$ and in cerebellar glomeruli /11/ where, after deafferentation, the otherwise exclusively postsynaptic dendrites of relay cells /10/ or granule neurons $/ 11 /$, both dendritic types were shown to develop axonal, presynaptic sites to form new, dendro-dendritic synapses, probably to compensate for the lost axo-dendritic synaptic junctions. Such dendritic synaptogenesis occurred in brain regions (for example, the cerebellar cortex, some thalamic nuclei) where the neuronal basis of axonal-type reactive synaptogenesis (sprouting of local or extrinsic axons) is either negligible or lacking $/ 5 /$.

Previous studies in our laboratory have demonstrated the presence of both dendritic types /11/ and also a moderate axonal /12/ type of synaptogenesis in the granular layer of cerebellar cortex. In normal, intact cerebellar cortex, all nerve cells are classical neurons $/ 2,22 /$, the dendrites and somata of which exhibit only postsynaptic sites. Under abnormal conditions, however, as in organotypic cerebellar cultures $/ 18 /$, in cerebellar mutant mice $/ 29 /$, or in undercut, isolated cerebellar cortex $/ 11 /$, the granule cells develop presynaptic sites on the somata and dendritic processes. Similarly, the other neuron type of the granular layer, the Golgi neurons, accumulate synaptic vesicles in their dendritic processes. The observation that the newly formed presynaptic dendrites and somata were engaged in various synaptic arrangements indicates the potential of both nerve-cell types for deafferentation-caused compensatory reactions.

The cerebellar glomerulus is the main structural locus in the cerebellar cortex where reactive synaptogenetic processes have been observed, both during development and in adults. The structural organization of this complex synaptic structure has been described by several authors $12,9,16,22 /$. Accordingly, in the glomerulus two presynaptic elements, the excitatory mossy terminals and the inhibitory Golgi axon varicosities, establish multiple synaptic contacts with many dendritic processes of granule cells. Quantitative morphological and stereological studies $/ 16,17 /$ have provided the most important data about the number of participating neuronal processes and the number of synaptic junctions in simple type /17/ glomeruli. This information makes it possible to compare synaptic numbers between control and mossy fiber deafferented cerebellar glomeruli, that is, to express neosynaptogenetic plasticity in quantitative terms. In the present study, we used quantitative morphological and stereological methods to compare the structures of control and mossy-fiber deafferented, synaptically reorganized glomeruli.

\section{MATERIALS AND METHODS}

\section{Tissue preparation}

In two adult male rats the upper cerebellar vermis, including lobe 4 , was undercut by a surgical knife, resulting in a complete isolation of the vermal cortex. This procedure secures a complete transection of all afferents (climbing fibers, mossy fibers, and catecholamine fibers), as well as efferent (Purkinje) axons without disturbing the normal blood supply from the pial vessels to the isolated vermis. Fifteen days after the operation, the animals were perfused with a fixative solutions, consisting of $1 \%$ paraformaldehyde and $1 \%$ glutaraldehyde in $0.1 \mathrm{M}$ phosphate buffer ( $\mathrm{pH}$ 7.4). As a control, the normal cortices of two intact animals /17/ from the same brood were used after perfusion with the same aldehyde fixative.

Small blocks of the perfused vermal cortices were excised and (a) immersed in buffered $2 \%$ osmic acid ( $\mathrm{pH} 7.4)$, (b) dehydrated in ethanol, (c) stained for $60 \mathrm{~min}$ in $1 \%$ uranyl acetate dissolved in $70 \%$ ethanol, and then (d) embedded in Durkupan.

Serial ultrathin sections were cut using an LKB V Ultrotom. Ribbons of 120-250 consecutive sections were mounted on formvar-coated, singleslot grids and then stained with lead citrate. Four complete glomeruli from the control cerebellar cortex and six glomeruli from the deafferented 
cerebellar cortex were photographed at $12000 \times$ and analyzed for quantitation at $27000 \times$. The number of successive sections covering complete glomeruli were $131,123,159,170$ in the control glomeruli; and in the deafferented cortex: 110, 131, 194, 135, 193, 133.

Before the lead staining, a few sections were also immunostained for GABA, using the postembedding method of Somogyi and Hodgson 128/. The GABA antiserum (Arnel Co., New York) was used at a dilution of 1:3000. For the EM immunoreaction, $15 \mathrm{~nm}$ gold-labeled Immunogold goat anti-rabbit antibody was used.

\section{RESULTS}

\section{Structure of normal cerebellar glomerulus}

An electron micrograph of the normal, intact cerebellar glomerulus is presented in Fig.1. The clawlike, postsynaptic dendritic digits of the granule cell dendrites surround the large, bulbous, mossy terminal, which is usually located in the center of the glomerulus. A second type of axonal element, the thin, varicose Golgi axonal branches, can be seen at the periphery of the cerebellar glomerulus. The synaptic vesicles in the mossy terminal are, in most cases, large and spheroid, whereas the small Golgi axonal varicosities contain small, ovoid or flat, synaptic vesicles (Fig. 1, inset). The Fig. 1 inset also shows that the synaptic junctions between the mossy-terminal and the dendritic digits are asymmetric, whereas the synapses between the Golgi axonal varicosities and the granule-cell dendrites exhibit a symmetric morphology. In addition, nonsynaptic, symmetric attachment plaques between the dendrites or the dendritic digits of the granule cells can be seen frequently (Figs. $2,4,5,6)$.

\section{Mossy-fiber-deafferented cerebellar glomerulus}

Fifteen days after undercutting the vermal cortex, all mossy terminals disappeared from the isolated cerebellar cortex. In addition to the absence of mossy terminals, two main structural alterations could be seen in the deafferented cerebellar glomerulus. (a) In contrast to a normal glomerulus,
TABLE 1

Total granule cell dendrites and dendritic digits in control and mossy-fiber-deafferented cerebellar glomeruli

\begin{tabular}{cccc}
\hline Glomeruli & $\begin{array}{c}\text { Granule cell } \\
\text { dendrites (Grd) }\end{array}$ & $\begin{array}{c}\text { Dendritic } \\
\text { digits }\end{array}$ & $\begin{array}{c}\text { Number } \\
\text { digits/Grd }\end{array}$ \\
\hline Control $^{\mathrm{a}}$ & $53 \pm 2.1^{\mathrm{c}}$ & $208 \pm 30.8$ & $3.9 \pm 0.5$ \\
Deafferented $^{\mathrm{b}}$ & $52 \pm 10$ & $217 \pm 36.8$ & $4.3 \pm 0.1$ \\
\hline
\end{tabular}

"Mean of four glomeruli in each group; ${ }^{b}$ Mean of six glomeruli in each group; ${ }^{\top}$ Mean \pm S.E.M.

where the Golgi axons were exclusively located at the periphery of the synaptic complex, the GABAcontaining Golgi axons in the deafferented glomerulus were also seen to occur in the interior of the glomerulus, and the number of Golgi axonal varicosities appeared to be increased compared with that of the control. (b) As previously observed /11/, new heterologous synaptic contacts between dendritic digits of granule cells were found in the mossy-fiber-deprived glomeruli. The newly developed dendro-dendritic synapses were the asymmetric type, and the synaptic vesicles were large and spheroid.

\section{Quantitative data}

Four complete, simple glomeruli from intact and six complete, simple glomeruli from deafferented vermal cortex were included in the quantitative morphological analysis. (A simple glomerulus contains one mossy terminal; the much larger, complex glomeruli exhibit two or more mossy terminals.) The following data were collected:

1. The number of granule-cell dendrites within the glomerulus;

2. the number of dendritic terminals (digits);

3. the number of Golgi axonal varicosities;

4. the synaptic numbers in the control (mossy terminal to dendritic digits, Golgi axon to digits); and

5. the number of synapses in the deafferented glomerulus (Golgi axon to digits and dendrodendritic synaptic junctions).

The quantitative and stereological investigations revealed that the simple synaptic glomerulus in the intact cerebellar cortex is supplied on the average by 53 postsynaptic granule-cell dendrites (Table 1), each originating from separate granule cells. 


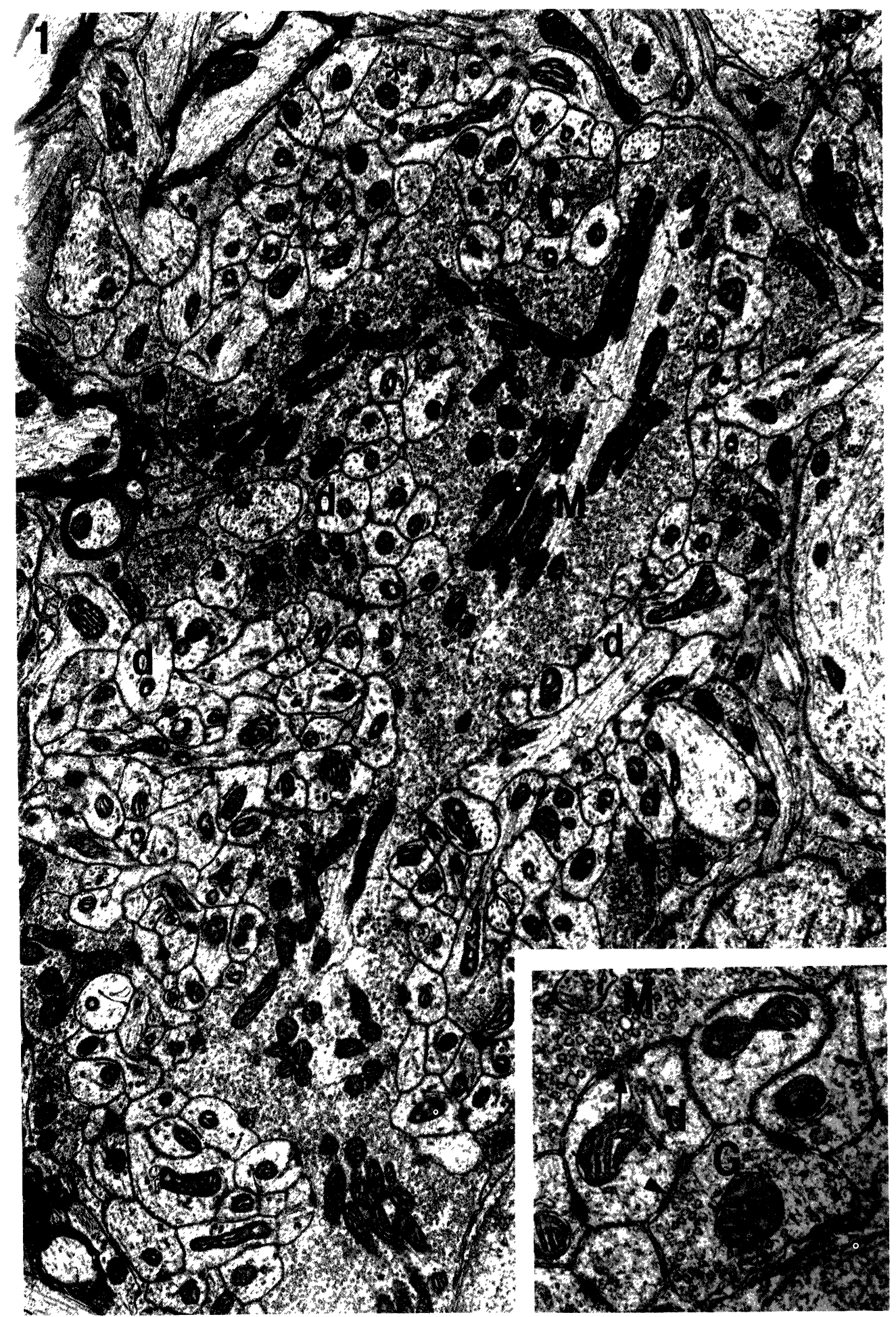

Fig. 1. Electron micrograph of a simple cerebellar glomerulus. The centrally located, huge mossy terminal ( $\underline{M})$ is surrounded by many digits (d) of granule-cell dendrites. Small Golgi axon varicosities (indicated by stars) are located at the periphery of the synaptic glomerulus. Inset: In the mossy terminal $(\underline{M})$, the synaptic vesicles are large and spheroid, while in the Golgi axon $(\underline{G})$ they are small and ovoid. $\uparrow$ indicates an asymmetric synaptic junction between the mossy terminal and dendritic digit (d); the same dendrite exhibits a symmetric synaptic contact (arrowhead) with Golgi axon. 


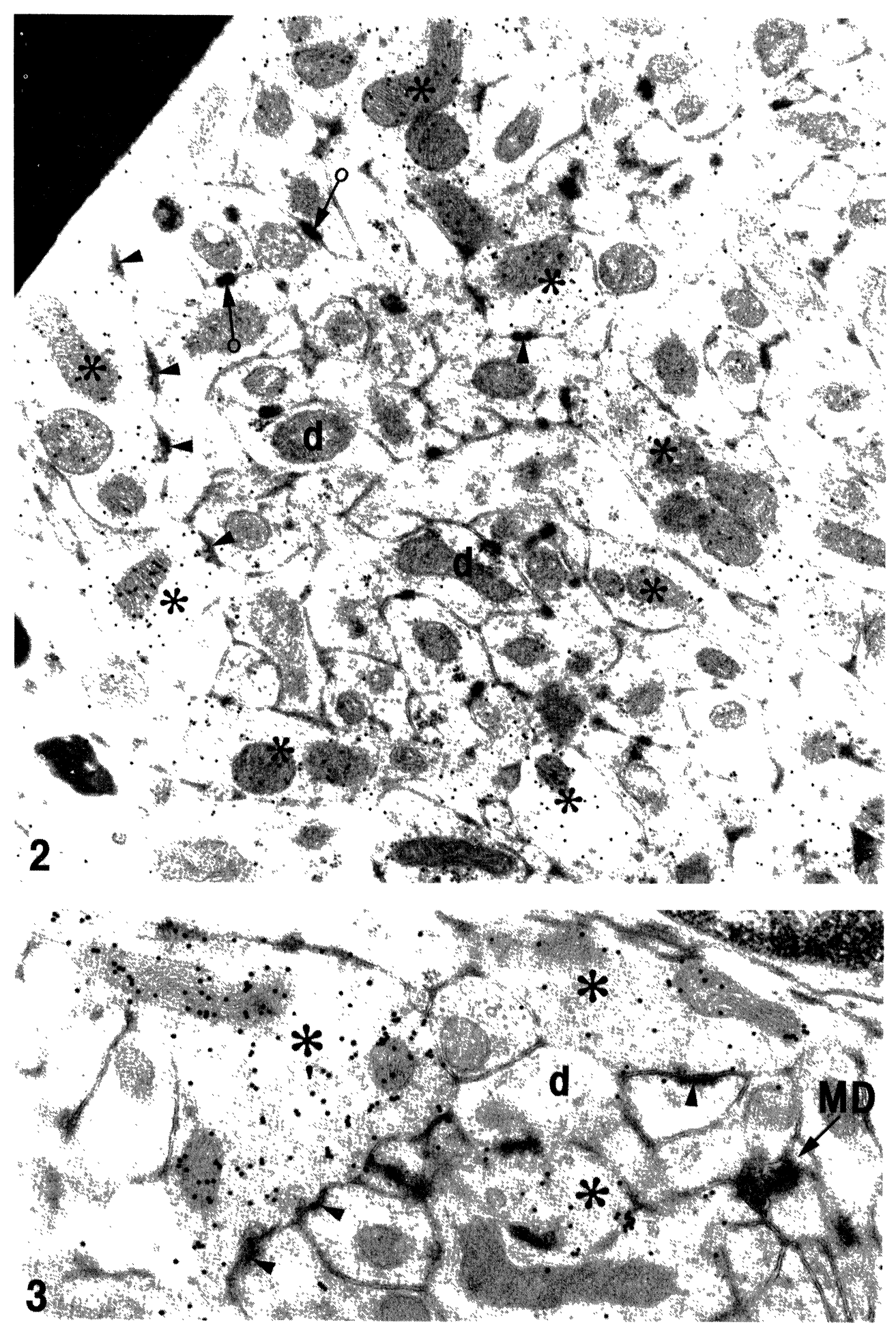

Fig. 2. Mossy-fiber deafferented cerebellar glomerulus, 30 days after surgical isolation of the cortex. GABA-containing, goldparticle-labeled Golgi axons ( $\underline{\text { tars }}$ ) are found not only at the periphery but also in the center of the deafferented glomerulus. di: dendritic digits; ringed arrow: dendro-dendritic, nonsynaptic symmetric attachment plaques.

Fig. 3. Cerebellar vermis, 30 days after undercutting the cortex. Gold-labeled, GABA-containing Golgi axons (stars) establish several synaptic contacts with dendritic digits. $\underline{\mathrm{MD}}$ : remnant of the degenerating mossy terminal. 

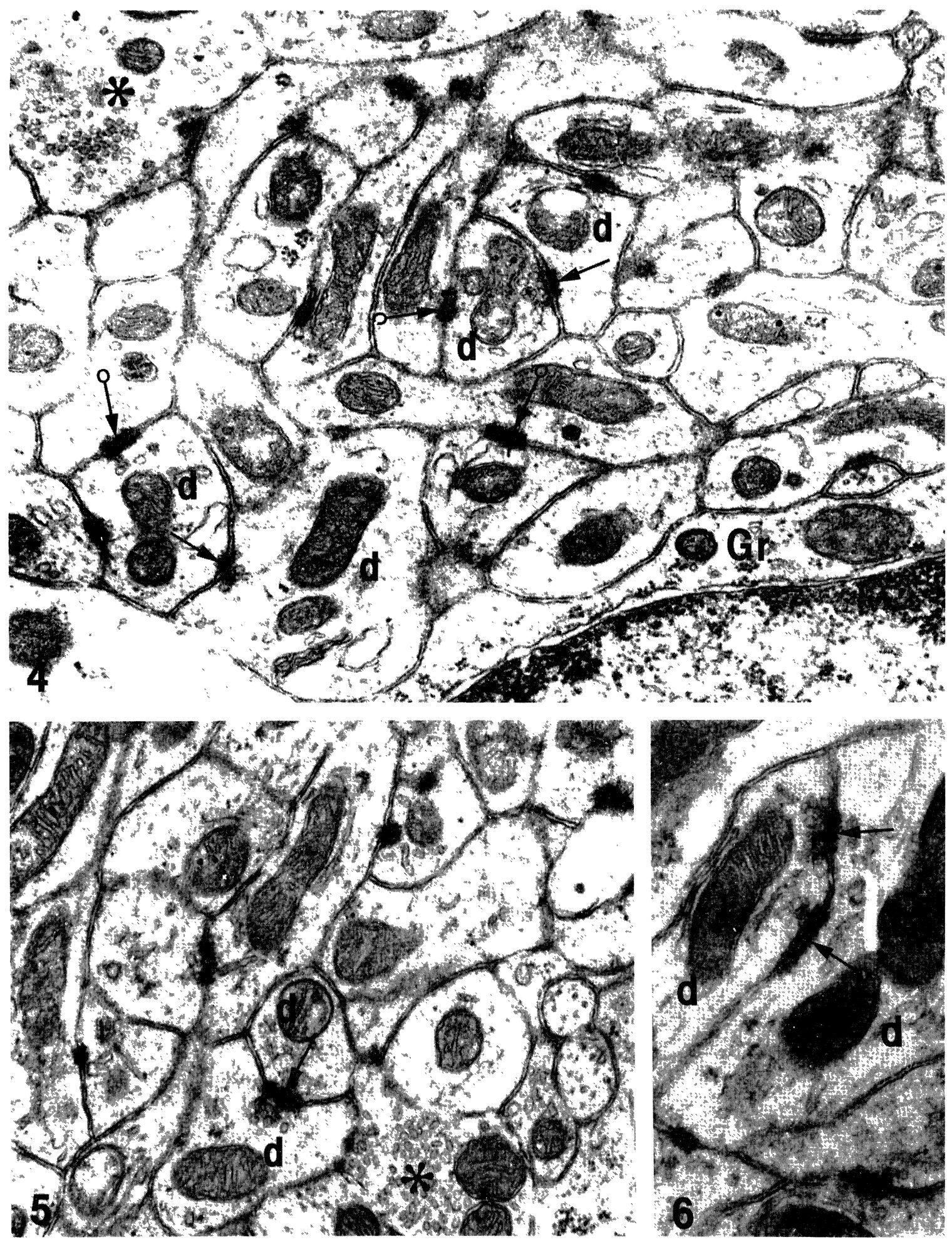

Figs. 4-6. Dendro-dendritic, asymmetric synapses $(\uparrow)$ between granule-cell dendritic digits (d) with large, spheroid synaptic vesicles; note the small, ovoid synaptic vesicles in Golgi axon terminal (star). Gr: granule-cell somata; ringed arrow: symmetric attachment plaques between granule-cell dendrites. 
TABLE 2

Number of synaptic junctions in control and mossy-fiber-deafferented cerebellar glomeruli

\begin{tabular}{ccccc}
\hline Cerebellar glomeruli & $\begin{array}{c}\text { Mossy-terminal } \\
\text { synapses (MT-syn) }\end{array}$ & $\begin{array}{c}\text { Golgi axon synapses } \\
\text { (Ga-syn) }\end{array}$ & $\begin{array}{c}\text { Dendro-dendritic } \\
\text { synapses }\end{array}$ & $\begin{array}{c}\text { Total number of } \\
\text { synapses }\end{array}$ \\
\hline Control $^{\mathrm{a}}$ & $145 \pm 14.2^{\mathrm{c}}$ & $\mathbf{8 7 \pm 2 3 . 8 ^ { * }}$ & 0 & $232 \pm 37.5$ \\
\hline Deafferented $^{\mathrm{b}}$ & 0 & $201 \pm 37.7^{*}$ & $52 \pm 10$ & $253 \pm 47.1$
\end{tabular}

${ }^{a}$ Mean of four glomeruli in each group; ${ }^{b}$ Mean of six glomeruli in each group; ${ }^{9}$ Mean \pm S.E.M.

*The difference between the control and deafferented is significant (U-test, one-sided, $\alpha=0.05$; Wilcoxon-Mann-Whitney /35/)

TABLE 3

Number of Golgi axon synapses and varicosities in control and mossy-fiber-deafferented cerebellar glomeruli

\begin{tabular}{cccc}
\hline $\begin{array}{c}\text { Cerebellar glomeruli } \\
\text { Control }^{\mathrm{a}}\end{array}$ & $\begin{array}{c}\text { Golgi axon synapses } \\
(\mathrm{Ga}-\mathrm{syn})\end{array}$ & $\begin{array}{c}\text { Golgi axon varicosities } \\
\text { (Ga-var) }\end{array}$ & $\begin{array}{c}\text { Ga-syn/Ga-var } \\
19 \pm 3.8^{*}\end{array}$ \\
\hline Deafferented $^{\mathrm{b}}$ & $87 \pm 23.8^{\mathrm{c} *}$ & $39 \pm 6.6^{*}$ & $4.50 \pm 0.4$ \\
\hline
\end{tabular}

${ }^{a}$ Mean of four glomeruli in each group; ${ }^{b}$ Mean of six glomeruli in each group; ${ }^{\circ}$ Mean \pm S.E.M.

*The difference between the control and deafferented is significant (U-test, one-sided, $\alpha=0.05$; Wilcoxon-Mann-Whitney /35/).

A granule-cell dendrite emitted an average of 4 dendritic digits. As shown in a previous paper /17/, all dendritic digits had synaptic connections to mossy terminals, to Golgi axonal varicosities or to both. Table 1 shows that the number of granule-cell dendrites and their digits within the mossy-fiberdeafferented, simple glomerulus did not change.

The average number of excitatory mossy-fiber synapses established with granule-cell dendrites (mostly digits) was 145 within one glomerulus. In the control cerebellar cortex, an average of 87 inhibitory Golgi axon to granule-cell dendrite synapses made a total number of 232 synaptic junctions in one simple glomerulus. In the absence of mossy-fiber synapses in the deafferented glomerulus, an average of 52 newly formed, probably excitatory, dendro-dendritic synapses between granule cells were counted. When compared with the control numbers (87 versus 201, Tables 2 and 3), however, the number of inhibitory Golgi axonal synapses increased by two-and-a-half times. The increase in the Golgi axon synapses was accompanied by a similar increase of Golgi axonal (synaptic) varicosities, hence the number of synaptic junctions per axonal varicosity did not significantly change. Assembling the numerical data leads to the conclusion that the total number of synaptic junctions, although with a radically different proportion of excitatory and inhibitory synapses, was almost the same in both the control and the deafferented glomerulus (Table 2).

\section{DISCUSSION}

Our results suggest that after experimental removal of the main synaptic afferent, although significant reorganization was observed, the structural integrity of the cerebellar glomeruli was remarkably well preserved. Even in the absence of the mossy terminal, the number of granule-cell dendrites entering the synaptic complex did not change. Similarly, the number of claw-like dendritic terminals, the dendritic digits, receiving excitatory synapses from mossy endings in the intact glomerulus was the same in both control and deafferented glomeruli. Of special interest was the finding that despite the absence of the main excitatory synaptic input after mossy-fiber degeneration, the total number of synaptic junctions in the reorganized synaptic glomeruli did not change significantly (Table 2). The only important alteration was the proportion of excitatory and inhibitory synaptic junctions. In the intact glomeruli, 
excitatory synaptic junctions (supplied exclusively by mossy terminals) constituted the majority of the 232 individual junctions within one simple cerebellar glomerulus. By contrast, in the reorganized glomeruli the presumably inhibitory junction by Golgi-axon varicosities became the dominant synaptic type, whereas the newly formed dendrodendritic (probably excitatory) synapses between the granule cells represented only one-fifth of all synaptic junctions.

The quantitative data of the reorganized cerebellar glomeruli demonstrated a remarkable constancy, as well as plasticity of the neuronal elements building up this complex synaptic arrangement. The somewhat unexpected observation that the number of postsynaptic granule-cell dendrites within one glomerulus does not change after mossy-fiber deafferentation might be due to the presence of the intricate network of dendro-dendritic (and a few axo-dendritic) attachment plaques in the reorganized glomeruli. The nonsynaptic, symmetric attachment structures, called contactus adherens /26/, mechanically bind one single dendritic digit to 3-5 neighboring digits $/ 17 /$, resulting in a tightly interconnected network of about 50 granule-cell dendrites, the main recipient element of axonal input in the cerebellar glomerulus. Therefore, the presence of contactus adherens between granule-cell dendrites in the deafferented glomerulus might explain, at least in part, the survival and maintenance of dendrites and dendritic digits after mossy-fiber degeneration.

A second factor contributing to the survival of granule-cell dendritic profiles appears to be that the number of synapses belonging to the postsynaptic nerve cells remained unchanged, regardless of the excitatory or inhibitory nature of the new presynaptic element. A related finding was reported by Hillman and Chen / 14 / in experiments leading to a reduction of the parallel fiber/Purkinje cell ratio in the cerebellar cortex. The authors interpreted their results as providing morphological evidence for a constancy of the synaptic area, determined intrinsically by the (postsynaptic) recipient nerve cell. Another, although also indirect, piece of morphological evidence for the constancy of the synaptic surface was provided by Field and Raisman $13 /$, who demonstrated that in the sympathetic ganglion, the postsynaptic ganglion cells cannot increase their synaptic surface, even in the presence of an excess of presynaptic elements, indicating that not only "down-grading" but also "up-grading" of the synaptic surface per neuron is-if at all possible-a rather limited potential of nerve cells.

In another experimental model [after partial, deafferentation (enucleation) of the thalamic Lateral Geniculate Nucleus (LGN)], the absence of postsynaptic nerve-cell degeneration was explained $/ 6 /$ by the presence and survival of intrageniculate (inhibitory) and corticogeniculate (excitatory) terminals, which would have a sustaining effect on the postsynaptic neurons that they contact. Experimental proof for this suggestion was obtained by Somogyi et al. $/ 27 /$ who found that the removal of the excitatory optic afferents from the LGN was compensated by a reorganization of the cortical (excitatory) input to the partially deafferented LGN neuron, so that the synaptic-area surface of the nerve cell did not decrease.

In contrast to the LGN, where the removal of one excitatory input to the postsynaptic neurons could be compensated by at least two other surviving excitatory afferents, in the cerebellar glomerulus (where the only excitatory axon-the mossy fiber-was removed), other axonal sources of excitatory synapses replacing the lost mossy synaptic junctions were absent. Instead new synaptic contacts, resupplying the partially denervated granule-cell dendrites, were provided by the inhibitory Golgi axons and, unexpectedly, by the production of dendro-dendritic synapses. Under normal conditions, dendro-dendritic synapses were not observed in the cerebellar cortex.

Their appearance after deafferentation is a clear sign of the expression of the morphological plasticity of the granule neurons. In the absence of axonal sprouting of the granule cells, the "axonization" of the otherwise exclusively postsynaptic dendrites might be a partial answer to the loss of mossy synapses. In the normal glomeruli, however, whereas excitatory mossy-fiber synapses made up the majority (62\%) of all individual junctions, in the reorganized glomeruli dendro dendritic (excitatory) junctions represented only one-fifth of all synapses, and the inhibitory Golgi axons became the dominant type.

The huge increase of Golgi axonal synaptic junctions (four-fifths of all synapses within the 
reorganized glomerulus) also demonstrated the morphogenetic potential of this neuron to react to deafferentation by producing new synapses. This phenomenon is accomplished through a moderate sprouting of the Golgi axon, as indicated by the numerical increase of the synapse-bearing axonal varicosities. (Ramon y Cajal $/ 25 /$ also observed a slight hypertrophy of Golgi axons upon deafferentation). Participation of GABAergic inhibitory elements through hypertrophy or sprouting of their axons in the reorganization of partially deafferented thalamic nuclei $/ 13,21,33 /$ has been reported previously. The results of the present study not only confirm these findings but also provide quantitative, morphological evidence for the active participation of inhibitory axons in the synaptic reorganization of the deafferented cerebellar glomerulus.

The question of the functional significance of the synaptic reorganization of deafferented cerebellar glomerulus awaits further investigations, including electrophysiological, receptor-immunocytochemical, pharmacological approaches. But nevertheless, the present morphological observations have uncovered a dormant synaptogenetic potential of two types of cerebellar neurons, the granule and the Golgi cells in the deafferentation-induced synaptic reorganization of the cerebellar glomerulus.

\section{REFERENCES}

1. Bromberg MB, Pamel G, Stephenson BS, Young AB, Penney JB. Evidence for reactive synaptogenesis in the ventrolateral thalamus and red nucleus of the rat: Changes in high-affinity-glutamate uptake and numbers of corticofugal fiber terminals. Exp Brain Res 1987; 69: 53-59.

2. Eccles JC, Ito M, Szentágothai J. The Cerebellum as a Neuronal Machine. Berlin, Heidelberg, New York: Springer Verlag, 1967.

3. Field PM, Raisman G. The density of reinnervation of adult rat superior cervical symphatetic ganglionic neurons is limited by the number of available postsynaptic sites. Brain Res 1985; 360: 398-402.

4. Frotcher M, Nitsch C, Hassler R. Synaptic reorganization in the rabbit hippocampus after lesion of commissural afferents. Anat Embryol 1981; 163: 301-309.

5. Guillery RW. Experiments to determine whether retinogeniculate axons can form translaminar collateral sprouts in the dorsal lateral geniculate nucleus of the cat. J Comp Neurol 1972; 46: 407-420.

6. Guillery RW. Quantitative studies of transneural atrophy in the dorsal lateral geniculate nucleus of cats and kittens. J Comp Neurol 1973; 49: 423-438.

7. Hámori J. "De novo" formation of synapses by experimentally induced presynaptic dendrites in adult mammalian brain. Acta Biol Acad Sci Hung 1982; 33: 173-187.

8. Hámori J. Morphological plasticity of postsynaptic neurones in reactive synaptogenesis. J Exp Biol 1990; 153: 251-260.

9. Hámori J. Anatomy and neurochemical anatomy of the cerebellum. In: Plaaitakis A, ed, Cerebellar Degenerations: Clinical Neurobiology. Boston: Kluvier Academic Publisher, 1992; 11-57.

10. Hámori J, Silakov VL. Plasticity of relay neurons in dorsal lateral geniculate nucleus of the adult cat: Morphological evidence. Neuroscience 1980; 5 20732077.

11. Hámori J, Somogyi J. Presynaptic dendrites and perikarya in deafferented cerebellar cortex. Proc Natl Acad Sci USA 1982; 79: 5093-5096.

12. Hámori J, Somogyi J. Formation of new synaptic contacts by Purkinje axon collaterals in the granular layer of deafferented cerebellar cortex of adult rat. Acta Biol Hung 1983; 34: 163-176.

13. Hámori J, Takács J, Verley $R$, Petrusz $P$, FarkasBargeton E. Plasticity of GABA- and glutamatecontaining terminals in the mouse thalamic ventrobasal complex deprived of vibrissal afferents: An immunogold electron microscopic study. J Comp Neurol 1990; 302: 739-748.

14. Hillman DE, Chen S. Vulnerability of cerebellar development in malnutrition. II. Intrinsic determination of total synaptic area on Purkinje cell spines. Neuroscience 1981; 6: 1263-1275.

15. Hoff SF. Lesion-induced transneural plasticity in the adult rat hippocampus. Neuroscience 1986; 19: 12271233.

16. Jakab RL. Three-dimensional reconstruction and synaptic architecture of cerebellar glomeruli in the rat. Acta Morph Hung 1989; 37: 11-20.

17. Jakab RL, Hámori J. Quantitative morphology and synaptology of cerebellar glomeruli in the rat. Anat Embryol 1988; 179: 81-88.

18. Kim SU. Granule cell with somatodendritic synapse in organotypic cultures of mouse cerebellum. Exptl Neurol 1974; 45: 659-662.

19. Matthews DA, Cotman C, Lynch G. An electron microscopic study of lesion-induced synaptogenesis in the dentate gyrus of adult rat. II. Reappearance of morphologically normal synaptic contacts. Brain Res 1976; 115: 23-41.

20. Murakami F, Katsumaru H, Saito K, Tsukahara N. A quantitative study of synaptic reorganization in red 
nucleus neurons after lesion of the nucleus interpositus of the cat: An electron microscopic study involving intracellular injection of horseradish peroxidase. Brain Res 1982; 242: 41-53.

21. Négyessy L, Takács J, Mogensen J, Divac I, Hámori J. Synaptic reorganization of the mediodorsal thalamic nucleus in adult rat following chronic prefrontal cortical lesions. J Brain Res 1995; 3: 433-441.

22. Palay SL, Chan-Palay V. Cerebellar Cortex: Cytology and Organization. Berlin, Heidelberg, New York: Springer Verlag, 1974.

23. Raisman G. Neuronal plasticity in the septal nuclei of the adult rat. Brain Res 1969; 14: 25-48.

24. Raisman G, Field P. A quantitative investigation of the development of collateral innervation after partial deafferentation of the septal nuclei. Brain Res 1973; 50: 341-364.

25. Ramon y Cajal S. Degeneration and Regeneration of the Nervous System. New York: Haffner, 1959; 629.

26. Rose O, Grund C, Reinhardt S, Starzinski-Polwitz A, Franke WW. Contactus adherens, a special type of plaque-bearing adhering junction containing M-cadherin in the granule-cell layer of the cerebella glomerulus. Proc Natl Acad Sci USA 1995; 92: 60226026.

27. Somogyi J, Eysel U, Hámori J. A quantitative study of morphological reorganization following optic deafferentation in the adult cat dorsal lateral geniculate nucleus. J Comp Neurol 1987; 255: 341-350.

28. Somogyi P, Hodgson AJ. Antiserum to $\gamma$-aminobutyric acid. III. Demonstration of GABA in Golgi- impregnated neurons and in conventional electron microsocopic sections of cat striate cortex. J Histochem 1985; 33: 249-257.

29. Sotelo C. Anatomical, physiological and biochemical studies of the cerebellum from mutant mice. II. Morphological study of cerebellar cortical neurons and circuits in the weaver mouse. Brain Res 1975; 94: 1944.

30. Steward O, Vinsant SL. The process of reinnervation in the dentate gyrus of the adult rat: A quantitative electron microscopic analysis of terminal proliferation and reactive synaptogenesis. J Comp Neurol 1983; 214: 370-386.

31. Steward O, Vinsant SL, Davis L. The process of reinnervation in the dentate gyrus of adult rats: An ultrastructural study of changes in presynaptic terminals as a result of sprouting. J Comp Neurol 1988; 267: 203-210.

32. Takács J, Hámori J. Morphological plasticity of dendrites in adult brain. Acta Neurobiol Exp 1990; 50: 109-114.

33. Takács J, Hámori J, Silakov V. GABA-containing neuronal processes in normal and cortically deafferented dorsal lateral geniculate nucleus of the cat: An immunogold and quantitative EM study. Exp Brain Res 1991; 83: 562-574.

34. Tsukahara N. Synaptic plasticity in the red nucleus. In: Szentágothai J, Hámori J, Palkovits $M$, eds, Regulatory Functions of the CNS Subsystems, Adv Phys Sci, Vol. 2. Oxford: Pergamon Press, Budapest Akademiai Kiako, 1981; 1-20. 

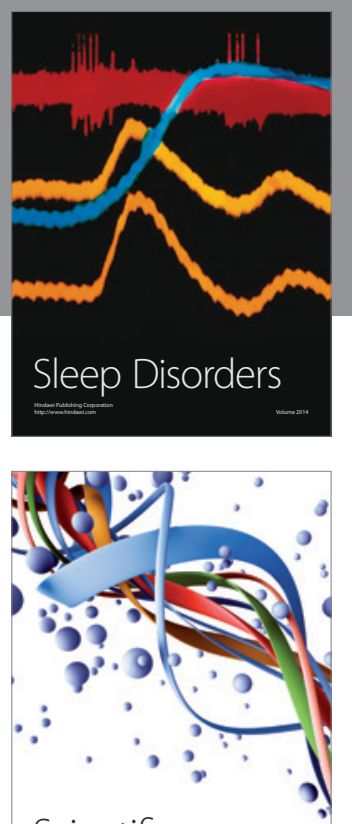

Scientifica
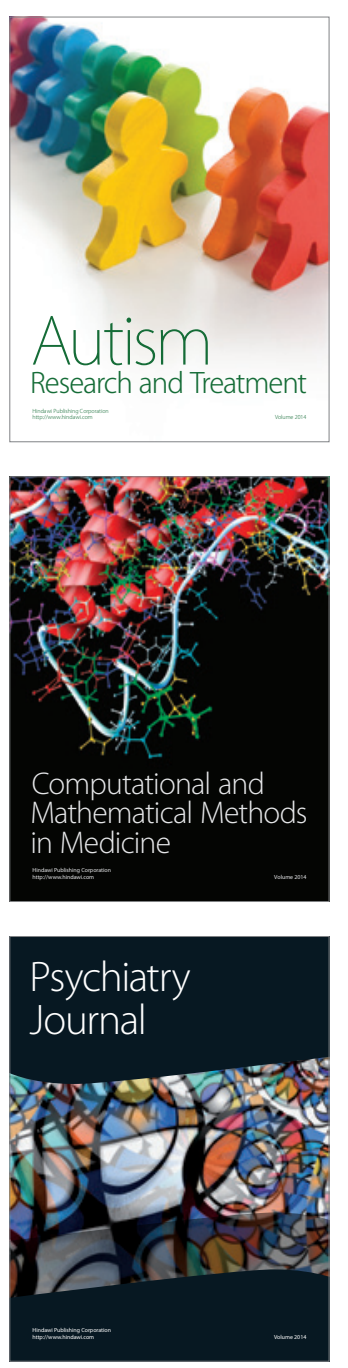
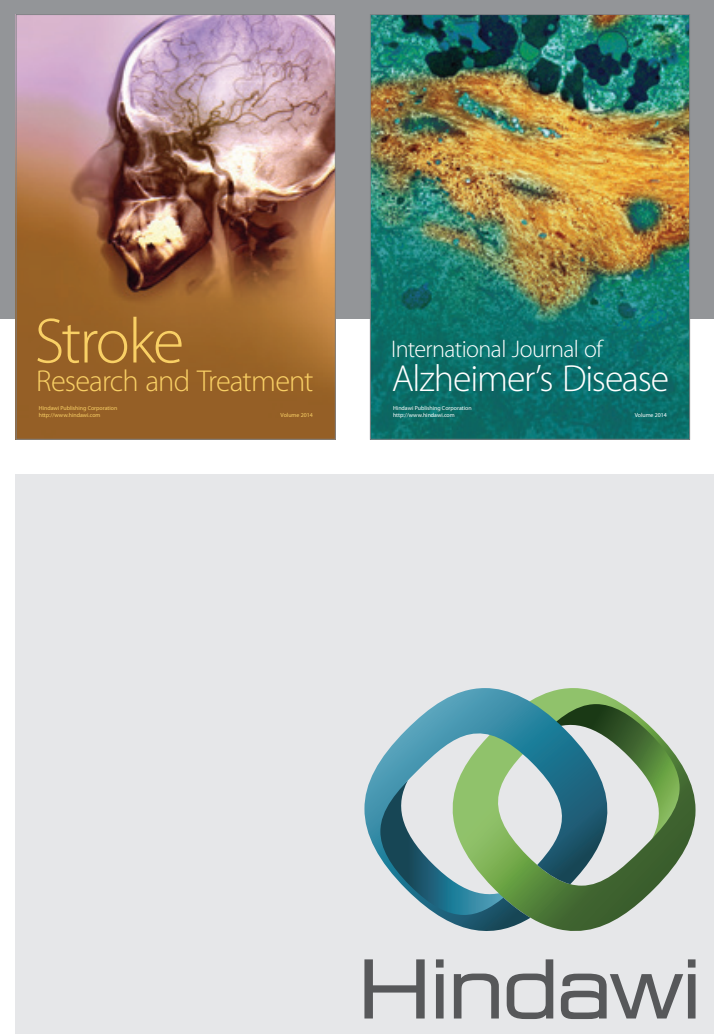

Submit your manuscripts at

http://www.hindawi.com
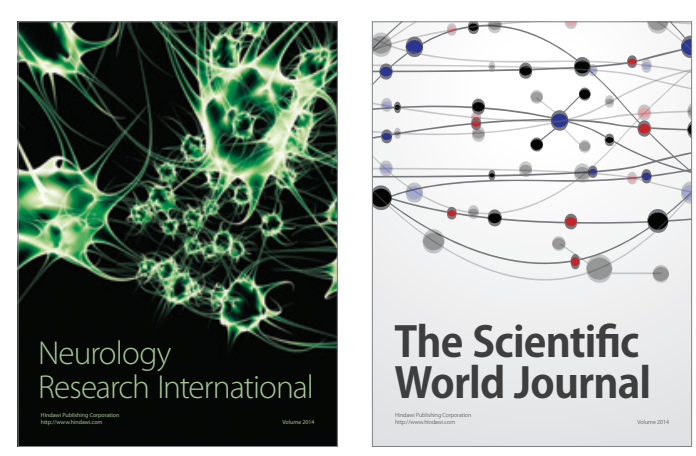

The Scientific World Journal

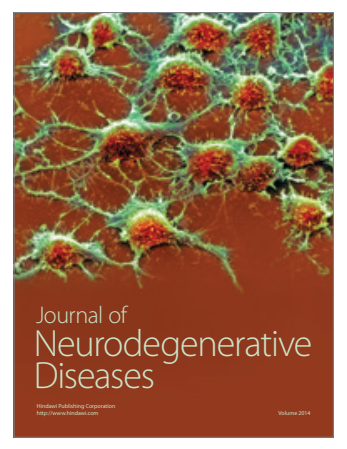

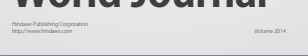

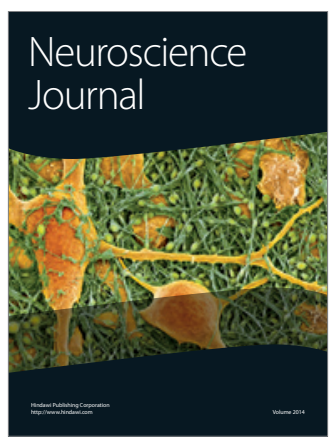

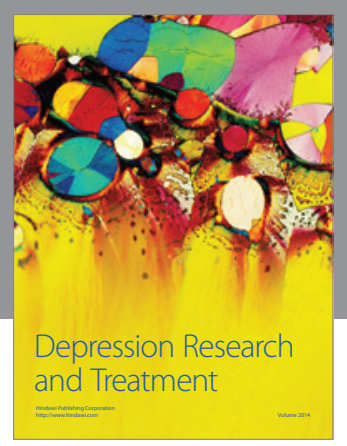
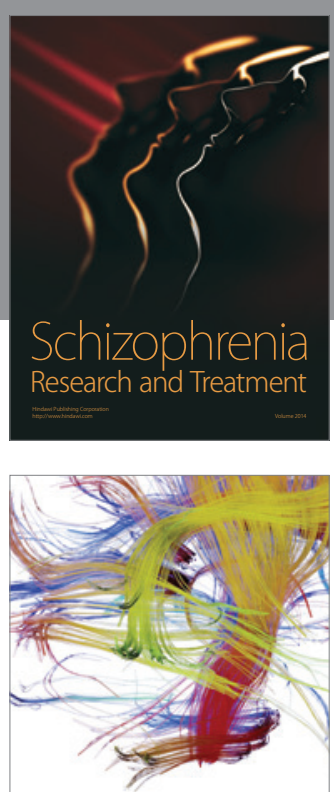

Brain Science

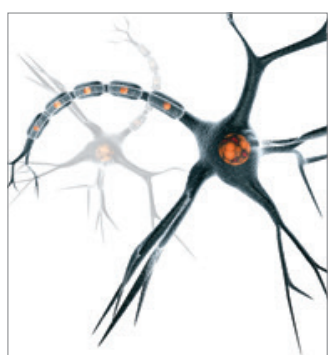

Neural Plasticity
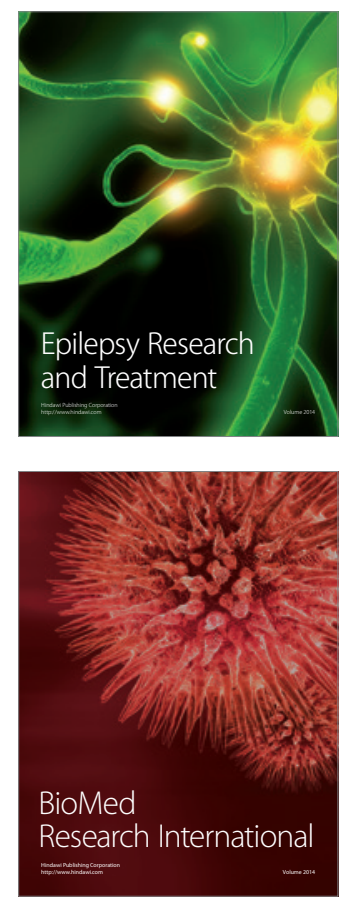

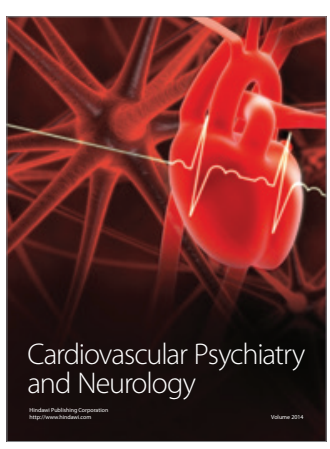

Parkinson's

Disease
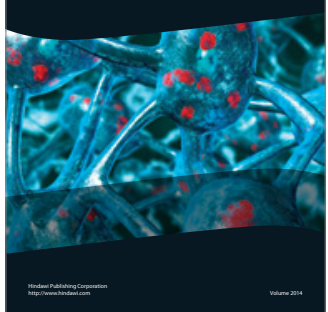